\title{
GOLD PLATING ON AM-FDM ABS COMPONENTS
}

\author{
D. Shani1, A. Inberg², D. Ashkenazi3*, Y. Shacham-Diamand2,4, \\ A. Stern 1,5
${ }^{1}$ Department of Mechanical Engineering, Afeka Academic College of Engineering, Tel Aviv, 69107, Israel
${ }^{2}$ School of Electrical Engineering, Tel Aviv University, Ramat Aviv 6997801, Israel
${ }^{3}$ School of Mechanical Engineering, Tel Aviv University, Ramat Aviv 6997801, Israel
${ }^{4}$ Department of Materials Science and Engineering, Tel Aviv University, Ramat Aviv 6997801, Israel
${ }^{5}$ Department of Materials Engineering, Ben-Gurion University of the Negev, Beer Sheva 8410501, Israel
*Corresponding author's e-mail address: $\underline{\text { dana@eng.tau.ac.il }}$

\begin{abstract}
Fused Deposition Modeling is one of the most common Additive Manufacturing methods for polymers. For some applications, parts manufactured by this method need post-printing surface coating. The present research aims at examining the surface finishing properties of Fused Deposition Modeling Acrylonitrile Butadiene Styrene parts coated for the first time with laboratory-developed electroless gold. Such coating can be applied for electrical purposes and as a decorative cover for $3 D$-printed prototypes, as well as on top of printed replicas of archaeological artifacts. Gold was deposited by electroless plating on top printed disk-shaped specimens, making them look like an ancient artifact. The electroless gold film was studied by various methods, including dimensions and mass measurements, qualitative pilling test, multifocal light microscopy, optical profilometer and X-ray diffraction analysis. The gold layer thickness was studied as a function of deposition time. The laboratory-developed electroless gold coating was deposited from a cyanide free bath and was compared to a commercial one deposited from a cyanide bath. The results displayed high-quality gold, and a satisfactory appearance. The roughness of the laboratory gold plated samples was somewhat reduced as the thickness of the gold film was increased, and the surface appearance was improved correspondingly. The developed gold coating can be adapted for various applications, including $3 D$ printed artifacts for museum exhibitions.
\end{abstract}

KEYWORDS: Additive Manufacturing, Fused Deposition Modeling, Acrylonitrile Butadiene Styrene, printed material, electroless gold plating, surface coating.

\section{INTRODUCTION}

\subsection{AM-FDM Technology}

Additive Manufacturing (AM) by three-dimensional (3D) printing, is defined as the direct manufacturing technologies of producing 3D objects from digital data. AM can be done by applying various techniques of making a 3D solid object of almost any shape from a digital model. In contrast, subtractive manufacturing processes typically start with larger bulk material that successively removes surplus materials. AM has many advantages, including design freedom and manufacturing flexibility. Therefore, it enables the production of geometries that have been considered impossible (or at least very complicated) to create by conventional technologies. In fact, such geometries can be additive manufactured fast, adaptably and with fewer tools. A main advantage is that AM typically eliminates the requirement for tooling, such as molds, dies, or mechanical machining tools, which can make the introduction of new products extremely expensive - both in time and money [1], [2].

One of the most widely used AM technologies is the Fused Deposition Modeling (FDM) method, which is suitable for many engineering applications and is currently used with many types of thermoplastic materials [3]-[7]. FDM is commonly used for modeling, prototyping and production applications. The product generated by the FDM technique typically has three steps: pre-processing, production and post-processing. In pre-processing, a Computer-Aided Design (CAD) model is constructed and converted into STL (stereo-lithography) format. During the FDM process, the AM-FDM machine head, equipped with a robotic system, extrudes a small oval or elliptical shaped thermoplastic polymer under computer control to additively construct 3D 
objects layer-by-layer. The layers are created until completion of the model. The molten plastic filament is deposited to generate each layer with a definite building strategy and the fused material bonds with the layer beneath and solidifies, creating a permanent bonding between the printed layers [3]-[5]. In postprocessing, the model and any supports are removed and the surface of the model is then completed with different finishing methods. Current FDM materials allow real parts productions that are tough and hard enough for prototyping, functional testing and/or installation. Acrylonitrile Butadiene Styrene (ABS) is the most used material in AM-FDM applications today, including prototyping through design verification. ABS is sufficiently resistant to heat, chemicals and moisture, that allow FDM components to be used in various functional testing, depending upon the specific application [1], [2], [8]-[11].

FDM is a mechanical manufacturing technology, which works as follows: the source material, in the form of an elliptical shaped fiber, is extruded through a moveable nozzle head where it is deposited as a filament of molten material (raster) on a build-platform (bed). The rasters then solidify to form a solid layer of material; additional layers are next deposited on top of each other to additively build 3D objects [12], [13]. Different build strategies are used to control the fiber layout, consequently the discontinuous geometry for each layer. The most common build strategy is: (a) the layer perimeter is made by contour toolpaths and (b) the interior is filled with a back and forth pattern at an angle of $45^{\circ}$ to the $\mathrm{x}$-axis. The alternating layers are filled with a raster direction at $90^{\circ}$ to one another. The geometry of the bond zone, between individual fibers and layers, has a great influence on the strength and mechanical anisotropy developed by the built components. The inter-layer weakness that plagues current thermoplastic (e.g. ABS) parts, can be potentially improved by using better build strategies. Support material is commonly used to be responsible for a build substrate, if the printed components contain cavities and/or projections [8], [14], [15]. This additional material prevents the component from collapsing during the building process.
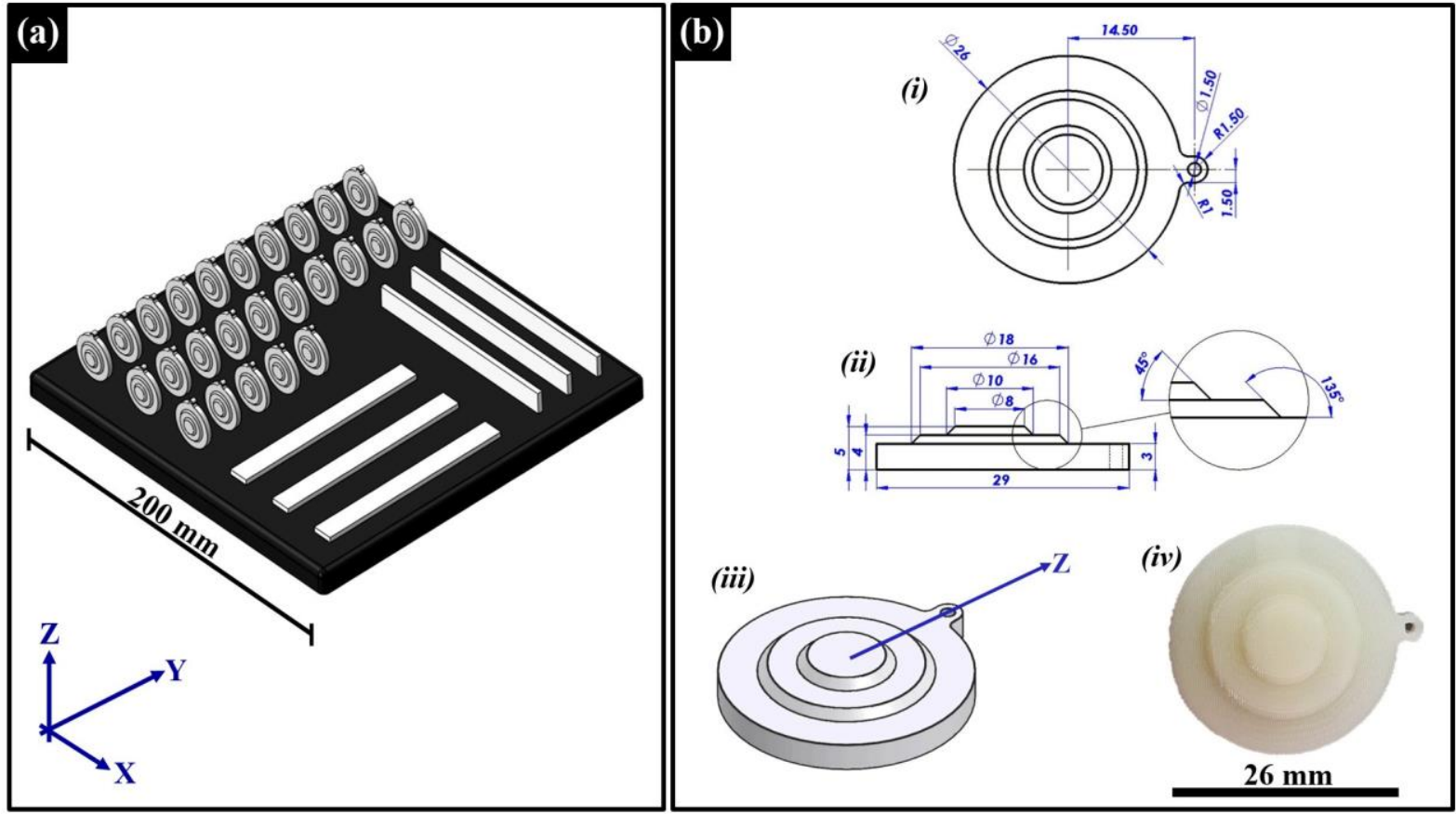

Fig. 1. The AM-FDM specimens: (a) the printing tray design showing the ABS printed disk specimens as well as three-point bending test specimens; and (b) the disk-shaped specimen: (i)-(iii) top, front, and isometric views of the solids CAD model, respectively ( $\mathrm{Z}$ is the print direction); and (iv) 3D-printed ABS disk specimen (obverse)

\subsection{Electroless Plating of Gold}

Metallic coatings of polymers, among them ABS, are widely used for various reasons: shielding the substrate from damage because of erosion and light (i.e. mainly visible and UV) induced damage, improving electrical, thermal, optical and mechanical properties of the surface, as well as for decoration considerations. Metal coating can be deposited on top of ABS following a chemical pretreatment process, with or without mechanical abrasion [16]. Various metals and alloys can be deposited; gold $(\mathrm{Au})$ is of special interest because of its good electrical and optical properties, its chemical stability and its unique appearance. Gold depositions are often achieved by physical or chemical vacuum deposition methods (PVD or CVD), and electroplating. However, since this study deals with ornamental and decoration 
coating of complex 3D printed structures, with a lot of hidden (e.g. shadowed) areas, the electroless deposition is preferred here. Electroless plating has been widely used as an industrial process since the nineteenth century [17]. This method is rather simple and inexpensive; it operates at rather low temperatures, offers high selectivity and enables selfaligned and auto-catalytic depositions on nonconductive surfaces [17]-[23]. A conventional electroplating process of metals on top of $\mathrm{ABS}$ is divided into two major steps: (1) surface preparation and (2) metal plating [16].

The aim of this work was to develop an electroless gold plating for FDM printed ABS parts finishing. Although commercial baths are available, most of them are designed for either electronics or relatively smooth surfaces. There was a need to develop a special process suitable for 3D printing, where the surface is highly hydrophobic and rough, with unique scaled features that are characteristics of FDM. Therefore, goal oriented gold coatings produced in the laboratory especially for $3 \mathrm{D}$ printing of ABS had been studied, and were compared to commercial coatings. The parameters for obtaining high-performance gold-plating for AM ABS diskshaped specimens produced by FDM technology are presented and discussed here for the first time.

\section{EXPERIMENTAL PART}

\subsection{Specimens}

In this work, gold coatings were prepared on diskshaped AM-FDM ABS specimens (Fig. 1a, Table 1). The ABS disk-shaped samples used in the present research include two steps at the obverse side, each 1 $\mathrm{mm}$ high, and a flat surface on the reverse side (Fig. 1b). The disk-shaped sample was designed with the purpose to simulate, in a controlled environment, a general geometry of ancient coins.

The disk-shaped specimen was designed with a CAD (SolidWorks 2017) program and the ABS specimens were printed in the vertical $(Z)$ direction (Fig. 1) by using a STRATASYS Dimension Elite 3D (C) printer [8], [14], [15]. The maximum extrusion and building chamber temperatures were $\sim 285^{\circ} \mathrm{C}$ and $\sim 70$ ${ }^{\circ} \mathrm{C}$, respectively.

The nozzle speed during extrusion was up to $12.7 \mathrm{~mm} / \mathrm{sec}$. Based on the CAD model, the calculated surface area of the disk-shaped sample was $13.81 \mathrm{~cm}^{2}$. Note that this is the projected area, not taking into consideration the extra surface due to the surface roughness of the printed disk-shaped samples.

Table 1. The FDM ABS disk-shaped specimens, mass (M) and coating thickness before and after gold coating $(\mathrm{GC}=$ Gold Coating, ELD = electroless deposition). For the laboratory-developed coating, the mass gain $(\Delta \mathrm{M})$ includes the $\mathrm{Ag}, \mathrm{NiP}$ and the Au layers; for the commercial coating, the $\Delta \mathrm{M}$ includes the $\mathrm{Cu}, \mathrm{NiP}$ and the $\mathrm{Au}$

layers (the analytical balance instrument provides mass values with an approximation error of $\pm 0.0001 \mathrm{~g}$; the XRF instrument error is $\pm 0.1 \mu \mathrm{m}$ )

\begin{tabular}{|c|c|c|c|c|c|c|}
\hline \multirow[b]{2}{*}{ Sample } & \multirow[b]{2}{*}{ Process } & \multirow{2}{*}{$\begin{array}{l}\text { ELD } \\
\mathrm{Au} \\
(\mathbf{m i n})\end{array}$} & \multicolumn{3}{|c|}{ Measured mass (g) } & \multirow{2}{*}{$\begin{array}{l}\text { Gold layer thickness } \\
(\mu \mathrm{m}) \\
\text { XRF }\end{array}$} \\
\hline & & & $\begin{array}{l}\text { As } \\
\text { printed }\end{array}$ & $\begin{array}{l}\text { After } \\
\text { coating }\end{array}$ & $\begin{array}{l}\Delta \mathrm{M}-\mathrm{Mass} \\
\text { gain }\end{array}$ & \\
\hline 19 & \multirow{3}{*}{$\begin{array}{l}\text { Laboratory-developed GC } \\
\text { (BATH A) }\end{array}$} & 15 & 1.8071 & 1.86310 & 0.05600 & 0.108 \\
\hline 18 & & 30 & 1.8170 & 1.88970 & 0.07270 & 0.211 \\
\hline 23 & & 90 & 1.8089 & 2.05770 & 0.24880 & 0.898 \\
\hline $\begin{array}{l}1,2,3,5, \\
6\end{array}$ & $\begin{array}{l}\text { Commercial GC (BATH } \\
\text { B), (Interplate Ltd.) }\end{array}$ & $\sim 10$ & 1.81482 & 1.88619 & 0.07138 & $0.212 \pm 0.025$ \\
\hline
\end{tabular}

Table 2. Laboratory gold coating (BATH A) composition [24]

\begin{tabular}{|c|c|}
\hline Component & Concentration $(\mathbf{g} / \mathbf{l})$ \\
\hline $\mathrm{KAu}(\mathrm{CN})_{2}$ & $2-3$ \\
\hline $3 \mathrm{Nacitrate}$ & $45-50$ \\
\hline $\mathrm{NH}_{4} \mathrm{Cl}$ & $70-75$ \\
\hline $\mathrm{NaH}_{2} \mathrm{PO}_{2}$ & $8-10$ \\
\hline
\end{tabular}

\subsection{Coating Method}

A laboratory electroless bath (Table 2, BATH A) for gold plating was developed at Tel Aviv University (TAU); the application of this solution [24] is rather novel for $\mathrm{ABS}$ or on any $3 \mathrm{D}$ printed objects. The laboratory-developed gold coating was compared to a commercial coating produced from semi-bright bath (BATH B, Interplate Ltd, Israel). In the laboratorydeveloped process, the gold films were deposited on the disk-shaped specimens (Fig. 1b) at a temperature of $85{ }^{\circ} \mathrm{C}$. The electroless plating process steps are presented in the schematic illustration (Fig. 2) and described in detail below.

Prior to gold deposition, all the ABS specimens were first treated in a $10 \%$ solution of sodium hydroxide $(\mathrm{NaOH})$ and etched in a $\mathrm{CrO}_{3} / \mathrm{H}_{2} \mathrm{SO}_{4}$ solution, both for $15-20 \mathrm{~min}$ at $65^{\circ} \mathrm{C}$. After etching, the samples were carefully cleaned from the $\mathrm{Cr}$ ions in diluted (1:3) nitric acid $\left(\mathrm{HNO}_{3}\right), 12 \mathrm{~g} / \mathrm{l}$ solution of 
sodium dodecylsulfate (SDS) and again in diluted (1:3) $\mathrm{HNO}_{3}$. Each procedure above mentioned was performed at room temperature for $15 \mathrm{~min}$. Finally, the specimens were washed in hot $\left(70{ }^{\circ} \mathrm{C}\right)$ deionized water (DI) for 10 minutes. Before metallization, the surface of the samples was sensitized in $\mathrm{SnCl}_{2} / \mathrm{HCl}$ and activated in $\mathrm{PdCl}_{2} / \mathrm{HCl}$ solutions at room temperature for $0.5 \mathrm{~h}$ and $1 \mathrm{~h}$, respectively. Thin silver (about $300 \mathrm{~nm})$ and thick $(\sim 1 \mu \mathrm{m})$ nickel-phosphorus (NiP) interlayers were deposited in order to improve the adhesion of the gold coating to the ABS plastic and prevent pitting corrosion due to electrolyte diffusion. By adding $\sim 1 \mu \mathrm{m} \mathrm{NiP}$ interlayer on top of ABS substrate, the roughness of the substrate may be slightly reduced. Moreover, the wear resistance of the object may also be improved.
Gold electroless plating (BATH A, $85^{\circ} \mathrm{C}$ ) was performed at different time intervals up to 45 minutes [24]. The specimens were washed between and after each processing step in DI water. After the gold deposition, the samples were oven heated at $110^{\circ} \mathrm{C}$ for $30 \mathrm{~min}$ in air.

The laboratory-developed gold coatings were compared to commercial ones (Table 1). It should be noted here that commercial gold coatings were produced from cyanide solution, while the lab developed bath is cyanide free. Moreover, in order to improve $\mathrm{Au}$ adhesion to the ABS substrate, commercial gold coating (BATH B) was performed on the copper interlayer. After deposition, the gold films were heated at $180^{\circ} \mathrm{C}$ for 30 minutes in an air oven.

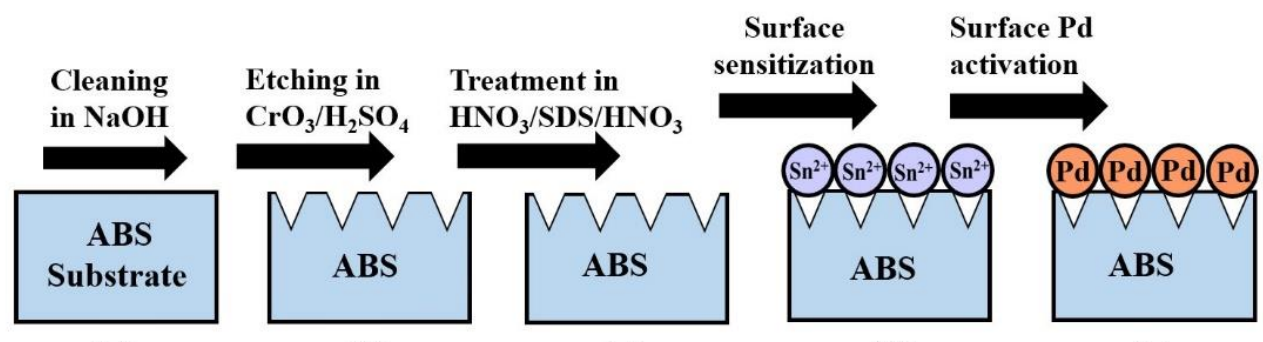

(a)

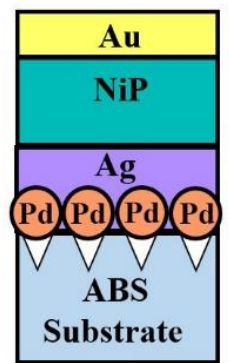

(h)

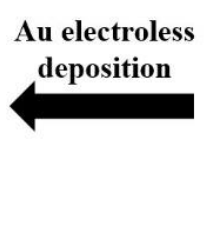

(b)

(c)

(d)

(e)

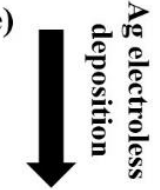

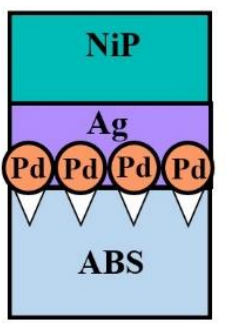

(g)
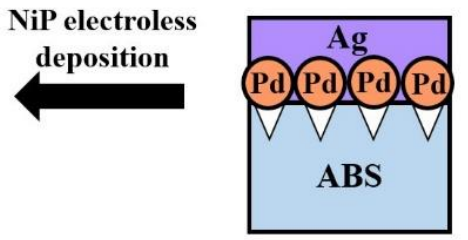

(f)

Fig. 2. Schematic flow chart of the laboratory-developed electroless gold-plating process for AM ABS substrate:

(a) the printed ABS substrate after cleaning its surface with sodium hydroxide; (b-c) etching and surface treatment in order to improve the surface wettability; (d) surface sensitization; (e) surface Pd activation; (f) Ag electroless deposition; (g) NiP electroless deposition; and (h) Au electroless deposition

\subsection{Characterization}

To characterize the surface of the printed FDM ABS samples before and after gold coating, visual testing (VT) inspection was performed to detect visible defects and discontinuities.

The FDM ABS printed disks were weighed before and after coating using an analytical balance (MRC ASB-220-C2) with a precision scale of $\pm 0.0001 \mathrm{~g}$ in order to calculate the estimated thickness of the thin gold coating (Table 1). Their dimensions (diameter and thickness) were taken with a digital micrometer. To characterize the gold layers, the following methods were used:

(a) The thickness of the gold film (Table 1, with instrument error is $\pm 0.1 \mu \mathrm{m}$ ) was measured by a calibrated high-resolution X-ray fluorescence (XRF) FISCHERSCOPE XRAY XDL 230 instrument. The examined area in each specimen was a $\sim 1 \mathrm{~mm}$ circle in diameter. All measurements were performed for $30 \mathrm{~s} \mathrm{each}$.

(b) An alpha-Step D-500 Stylus Profilometer instrument was used, with $0.1 \mathrm{~nm}$ vertical highresolution 2D profiling, for roughness measurements of the samples. This high resolution instrument has the capability of measuring heights from few nanometers up to $\sim 1$ $\mathrm{mm}$. The roughness was measured at different locations on each sample before and after gold deposition.

(c) A qualitative pilling test was performed on all coated samples with transparent vinyl tape to 
estimate the Au coating adhesion.

(d) A Panalytical Empyrean Powder Diffractometer equipped with a position sensitive detector X'Celerator was used for the X-ray diffraction (XRD) analysis. Data was collected in the conventional symmetrical (theta/2theta) BraggBrentano configuration by means of $\mathrm{Cu} \mathrm{K \alpha}$ radiation $(\lambda=1.541 \AA)$ at $40 \mathrm{kV}$ and $30 \mathrm{~mA}$.

(e) An advanced multifocal 3D LM (HIROX RH2000), equipped with high intensity LED lighting, integrated stepping motor and high resolution HD $(1920 \times 1200)$ live image operation, was used in order to examine to surface quality, topography and roughness before and after gold coating. No conventional metallographic crosssections of the coated samples could be performed due to the very thin gold film and because both the ABS substrate and the Au are very soft metals.

\section{RESULTS AND DISCUSSION}

\subsection{AM-FDM ABS Disk-Shaped Specimens}

VT inspection of the printed ABS disks (Fig. 1b) revealed rough surfaces on both obverse and reverse sides of the disk. The measured mass values of ABS as printed disk-shaped specimens (nos. 18, 19, 23) were between 1.8071-1.8229 g (Table 1), with average mass value of $1.811 \mathrm{~g}$, and the measured diameters were between $26.12-26.45 \mathrm{~mm}$.

The average measured root mean square (RMS) surface roughness was $18.81 \mu \mathrm{m}$ and the average value of the roughness analytical function $(\mathrm{Ra})$, also known as roughness arithmetic average deviation, was $15.72 \mu \mathrm{m}$.

The XRD analysis of the ABS substrate (3Dprinted reference sample) revealed amorphous structure (Fig. 3a), as expected from thermoplastic polymer. Phase identification from the received XRD data was done by using International Centre for Powder Diffraction Data (ICDD) data bases.

\subsection{Laboratory-Developed Gold Coating}

VT of the laboratory-developed gold-coated disks (specimens 18, 19, 23) showed a relatively uniform shiny lustrous gold appearance, with rough surface topography (Fig. 4a). Nevertheless, the coated samples were less rough than that of the as-printed (un-coated) ABS surface.

The measured mass values of the gold-coated specimens were between 1.8631-1.8897 g (Table 1). The qualitative pilling test of the coated samples revealed good quality coating. The measured thickness of the gold coating was $0.108-0.898 \mu \mathrm{m}$ (Table 1, XRF results $\pm 0.1 \mu \mathrm{m}$, and Fig. 5).

The coating process is controlled by two different deposition mechanisms (stage I and stage II, Fig. 5). In stage I the gold is deposited on top of the nickel-phosphorus film; this stage is controlled by a reaction replacement of nickel by gold. When the time of the process reaches $t_{c}$ (Fig. 5) the surface is totally covered with gold and stage II of the process begins; this stage is controlled by an auto-catalytic process.

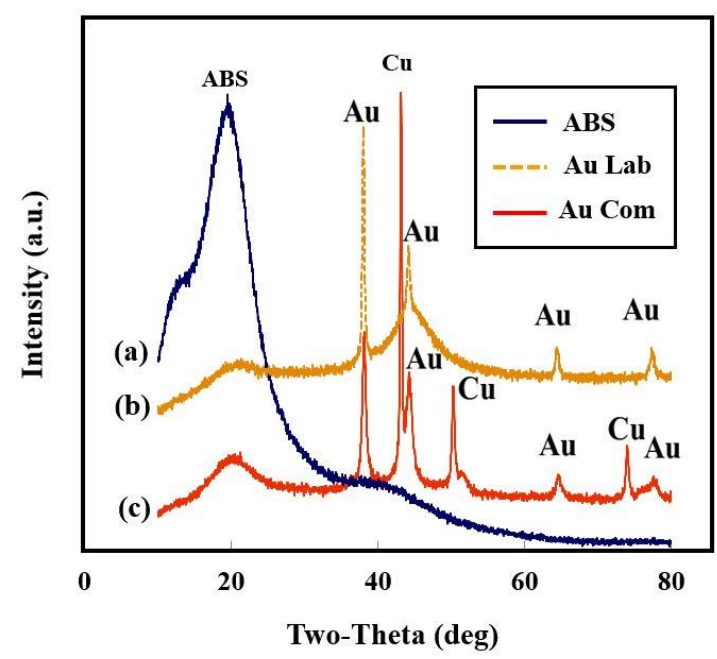

Fig. 3. XRD results of the: (a) ABS substrate sample;

(b) laboratory-developed gold-coated sample $(\mathrm{Au}$ thickness: $\sim 100 \mathrm{~nm}$ ); and (c) commercial gold-coated sample (Au thickness $\sim 200 \mathrm{~nm}$ )

The roughness of the 3D-printed surface is affected by the process parameters, such as the position and orientation of the part, as well as the presence of internal and external defects [25]. The average RMS and Ra surface roughness values were lower than the roughness of the as-printed specimens and the surface roughness was reduced as the deposition time was increased (Fig. 6).

The gold film thickness and its corresponding surface roughness could be controlled by setting the electroless deposition time.

The XRD analysis of the gold coating revealed characteristic peak of $\mathrm{Au}$ (Fig. 3b), indicating a highquality crystalline coating. The existence of Ni-P layer $(\sim 5$ at\% P) was not detected by the XRD analysis, because the layer probably has a very fine amorphous/nano-crystalline structure.

Multifocal observation of one of the gold-coated specimen (Figs. 4c, 4e, 7a, 8a) revealed the highquality coating.

The surface topography of the coated samples was similar to the as-printed specimens at the macroscopic level, however at the microscopic level the surface became smoother.

\subsection{Commercial Electroless Gold Coatings}

VT examinations of the commercial gold-coated disks (specimens 1-3, 5, 6) revealed relatively uniform shiny metal surfaces with rough surface topography; yet the coated surface was less rough than the asprinted surface (Fig. 4b). 

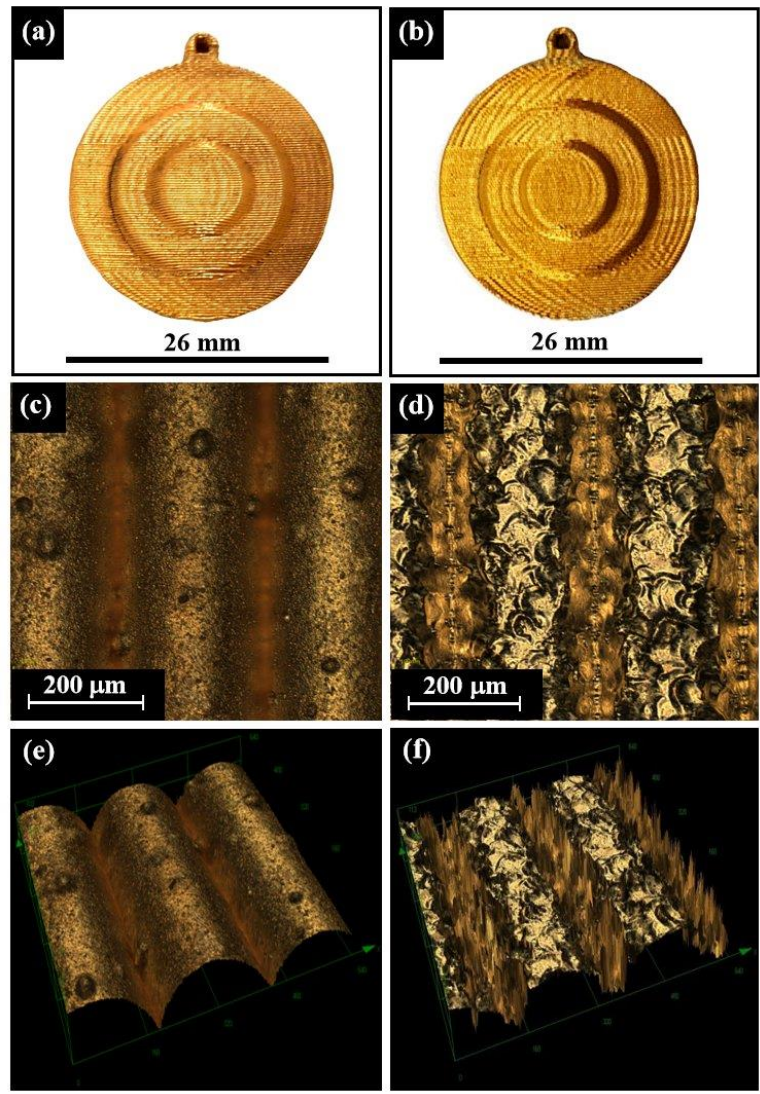

Fig. 4. Optical images of the printed ABS disk-shaped specimens covered with gold layer: (a) laboratory coated (Au thickness $\sim 100 \mathrm{~nm}$ ) specimen; (b) commercial coated (Au thickness $\sim 200 \mathrm{~nm}$ ) specimen;

(c)-(d) 2D LM images of the laboratory and commercial coated surfaces, respectively; (e)-(f) 3D LM images of the laboratory and commercial coated surfaces, respectively

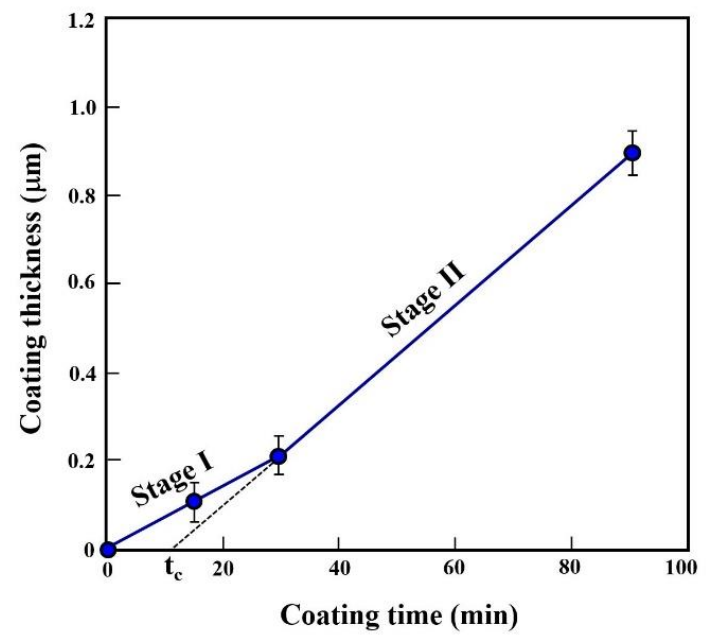

Fig. 5. Thickness of the laboratory-developed gold coating (measured by XRF) versus coating time

Multifocal observation of one of the gold-coated specimens (Figs. 4d, 4f, 7b, 8b) exposed the highquality coating. The surface topography of the coated samples was similar to the printed specimens at the macroscopic level, however at the microscopic level some smoothing of the surface had occurred.

The mass values of the coated specimens are between 1.8577-1.9095 $\mathrm{g}$ (Table 1, with average mass value of $1.8862 \mathrm{~g}$ ). Qualitative pilling tests performed on the gold layers confirmed the good coating-substrate adhesion. The measured thickness of the coating is $0.187-0.243 \mu \mathrm{m}$, with average value of $0.212 \pm 0.025 \mu \mathrm{m}$ (Table $1, \mathrm{XRF}$ results).

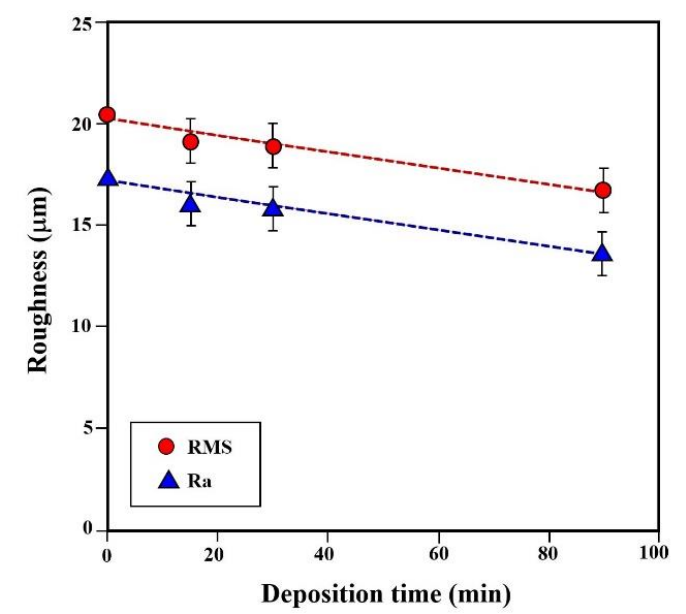

Fig. 6. The measured (Profilometer) roughness (RMS and $\mathrm{Ra}$ ) of the laboratory-developed gold coating versus coating time
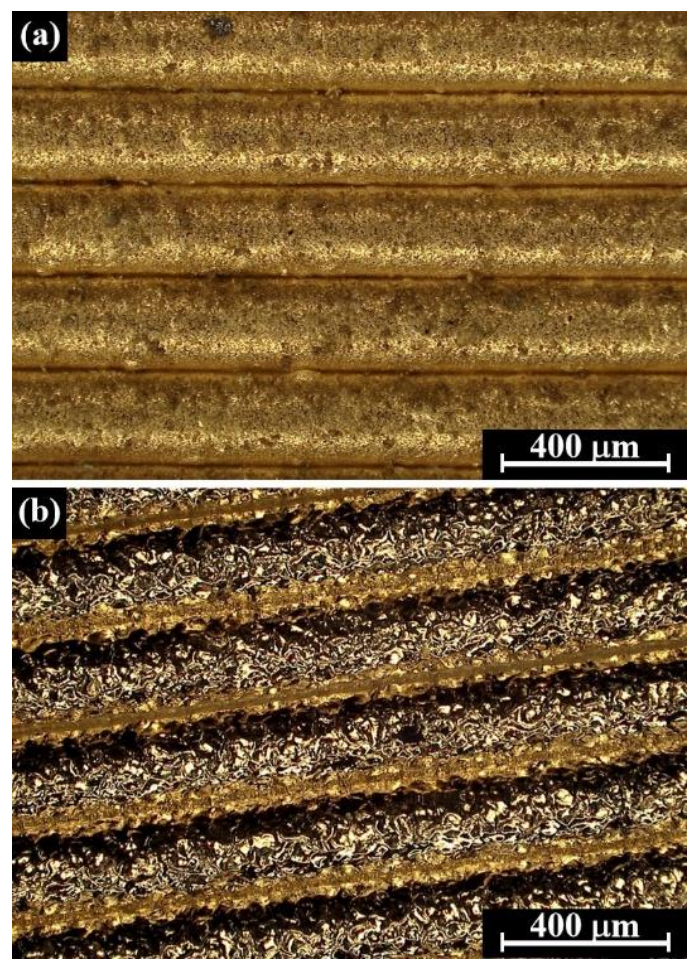

Fig. 7. Multifocal 3D LM images of the ABS printed substrate covered with: (a) laboratory-developed coating; and (b) commercial coated surfaces 
The XRD analysis of the coating revealed characteristic peaks of $\mathrm{Au}$ indicating a high-quality crystalline gold coating and characteristic peaks of a crystalline copper interlayer (Fig. 3c). The existence of $\mathrm{Cu}$ peaks in the XRD spectrum results from the high roughness of the ABS surface and correspondingly from the inhomogeneity of the commercial gold coating (Fig. 4d, 4f).

The current work is a part of an ongoing research. The effect of surface roughness on coating properties will be studied in the near future. Moreover, other electroless metal coatings, such as silver and copper, will be examined; however, this is beyond the scope of the present study.
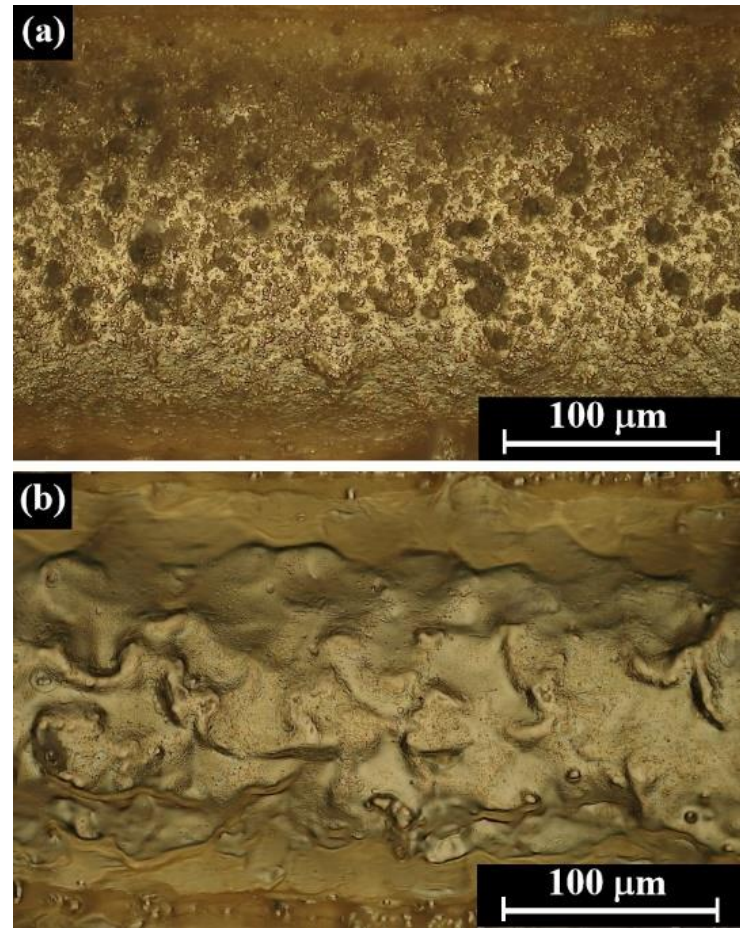

Fig. 8. Multifocal 3D LM images of the ABS printed substrate covered with gold, showing the microscopic morphology of the: (a) laboratory-developed coating; and (b) commercial coated surfaces

\section{SUMMARY}

The ABS polymer is widely used in AM-FDM applications. In some FDM printed parts, additional coating is needed to improve surface properties. For example, ABS replicas of ancient gold coins, as well as of expensive ancient gold jewelry can be successfully printed by the AM-FDM process and then coated with precious metals to be displayed to the public during exhibitions.

In the present research work, a simple laboratory-developed environmentally friendly electroless gold plating was applied for the first time on top of AM-FDM ABS to improve the surface appearance based on aesthetics considerations. The influence of the deposition time on the gold coating thickness and its roughness was examined. The deposition process is controlled by two mechanisms: (1) reaction replacement (nickel by gold) and (2) autocatalytic gold deposition (Fig. 5). An insignificant reduction in the ABS surface roughness was observed as a function of the gold film thickness. A solid gold coating with good surface coverage and crystalline structure has been confirmed both by HIROX observations and XRD analysis.

The laboratory-developed gold coating was also compared to a commercial one. VT observation revealed good quality and appearance of both electroless gold coatings applied on top of AM-FDM ABS disk-shaped specimens. The XRD analysis results of the ABS substrate revealed amorphous structure (Fig. 3a); that of the laboratory-developed gold coating revealed a crystalline gold coating (Fig. $3 \mathrm{~b}$ ); and that of the commercial coating revealed a crystalline gold coating, as well as crystalline $\mathrm{Cu}$ interlayer (Fig. 3c). The existence of $\mathrm{Cu}$ peaks results from the inhomogeneity of the commercial gold coating (Fig. 4d, 4f). Therefore, although the commercial coating was about two times thicker than the laboratory one (Table 1, for time interval of 10-15 min), the XRD (Fig. 3) and multifocal LM (Fig. 4) analysis clearly showed that the laboratory-developed coating was smoother and had less porosity than the commercial one. Therefore, the laboratory coating is more appropriate for decorative applications as museum exhibitions, and can be adapted for various applications.

\section{ACKNOWLEDGEMENTS}

The research was supported by the Afeka Academic College of Engineering and the Tel Aviv University to whom the authors are grateful. Thanks are also due to R. Burstein, Interplate Ltd, Israel, for the commercial gold coating, and to Dr. D. Mogilevsky and Prof. G. Kimmel, Department of Materials Engineering, Ben-Gurion University of the Negev, for the XRD analysis.

Thanks are also due to N. Dresler from the Afeka Academic College of Engineering for his assistance; and to H. Kravits, Microtech LTD (Israel) and E. Leonhardt, HIROX Europe for their technical support. The authors are also grateful to Annette Friedman for the English editing.

\section{REFERENCES}

[1] Singh S., Ramakrishna S., Singh R., Material issues in additive manufacturing: A review, Journal of Manufacturing Processes 25, 2017, pp. 185-200.

[2] Rios O., Carter W., Post B., Lloyd P., Fenn D., Kutchko C., Rock R., Olson K., Compton B., 3 D printing via ambient reactive extrusion, Materials Today Communications, 15, 2018, pp. 333336.

[3] Li L., Sun Q., Bellehumeur C., Gu P., Investigation of bond formation in FDM process, In: Solid Freeform Fabrication Symp., 2002, pp. $1-8$.

[4] Bellehumeur C., Li L., Sun Q., Gu P., Modeling of bond 
formation between polymer filaments in the fused deposition modeling process, Journal of Manufacturing Processes 6.2, 2004, pp. 170-178.

[5] Sun Q., Rizvi G. M., Bellehumeur C. T., Gu P., Effect of processing conditions on the bonding quality of FDM polymer filaments, Rapid Prototyping Journal 14.2, 2008, pp. 72-80.

[6] Turner B. N., Strong R., Gold S. A., A review of melt extrusion additive manufacturing processes: I. Process design and modeling, Rapid Prototyping Journal 20.3, 2014, pp. 192-204.

[7] Turner B. N., Gold S. A., A review of melt extrusion additive manufacturing processes: II. Materials, dimensional accuracy, and surface roughness, Rapid Prototyping Journal 21.3, 2015, pp. 250261.

[8] Shabat D., Rosenthal Y., Ashkenazi D., Stern A., Mechanical and structural characteristics of fused deposition modeling ABS material, The Annals of "Dunarea De Jos" University of Galati. Fascicle XII: Welding Equipment and Technology 28, 2017, pp. 16-24.

[9] Ngo T. D., Kashani A., Imbalzano G., Nguyen K. T., Hui D., Additive manufacturing ( $3 D$ printing): A review of materials, methods, applications and challenges, Composites Part B: Engineering 143, 2018, pp. 172-196.

[10] Bagsik A., Schöppner V., Klemp E., FDM part quality manufactured with Ultem* 9085, In the 14th International Scientific Conference on Polymeric Materials 15, September 2010, pp. 307315.

[11] Ahn S. H., Montero M., Odell D., Roundy S., Wright P. K., Anisotropic material properties of fused deposition modeling ABS, Rapid Prototyping Journal 8.4, 2002, pp. 248-257.

[12] Turner B. N., Strong R., Gold S. A., A review of melt extrusion additive manufacturing processes: I. Process design and modeling, Rapid Prototyping Journal 20.3, 2014, pp. 192-204.

[13] Turner B. N., Gold S. A., A review of melt extrusion additive manufacturing processes: II. Materials, dimensional accuracy, and surface roughness, Rapid Prototyping Journal 21.3, 2015, pp. 250261.

[14] Berger A., Sharon Y., Ashkenazi D., Stern A., Test artifact for additive manufacturing technology: FDM and SLM preliminary results, The Annals of "Dunarea De Jos" University of Galati Fascicle XII, Welding Equipment and Technology 27, 2016, pp. 29-37.
[15] Solomon A., Rosenthal Y., Ashkenazi D., Stern A., Structure and mechanical behavior of additive manufactured fused deposition modeling ABS. The Annals of "Dunarea De Jos" University of Galati. Fascicle XII: Welding Equipment and Technology 29, 2018, pp. 47-56.

[16] Olivera S., Muralidhara H. B., Venkatesh K., Gopalakrishna K., Vivek C. S., Plating on acrylonitrilebutadiene-styrene $(A B S)$ plastic: a review, Journal of materials science, 51.8, 2016, pp. 3657-3674.

[17] Estrada-Raygoza I. C., Sotelo-Lerma M., Ramírez-Bon R., Structural and morphological characterization of chemically deposited silver films, Journal of Physics and Chemistry of Solids 67, 2006, pp. 782-788.

[18] Paunovic M., Electrochemical aspects of electroless deposition of metals, Plating, 1968, pp. 1161-1167.

[19] Inberg A., Shacham-Diamand Y., Rabinovich E., Golan G., Croitoru N., Electroless-deposited Ag-W films for microelectronics applications, Thin Solid Films 389, 2001, pp. 213-218.

[20] Asher T., Inberg A., Glickman E., Fishelson N., ShachamDiamand Y., Formation and characterization of low resistivity sub-100 nm copper films deposited by electroless on SAM, Electrochimica Acta 54.25, 2009, pp. 6053-6057.

[21] Inberg A., Livshits P., Zalevsky Z., Shacham-Diamand Y., Electroless deposition of silver thin films on gold nanoparticles catalyst for micro and nanoelectronics applications, Microelectronic Engineering 98, 2012, pp. 570-573.

[22] Fishelson N., Inberg A., Croitoru N., Shacham-Diamand Y., Highly corrosion resistant bright silver metallization deposited from a neutral cyanide-free solution, Microelectronic Engineering 92, 2012, pp.126-129.

[23] Duhin A., Inberg A., Eliaz N., Gileadi E., Electroless plating of rhenium-based alloys with nickel, cobalt and iron, Electrochimica Acta 174, 2015, pp. 660-666.

[24] Krusenstern A., Galvanotechnik of noble metals (in Russian), Moscow, "Metallurgy" 1974, p. 91.

[25] Dey A., Yodo N., A systematic survey of FDM process parameter optimization and their influence on part characteristics, Journal of Manufacturing and Materials Processing 3(3), 2019, pp. 64-94. 